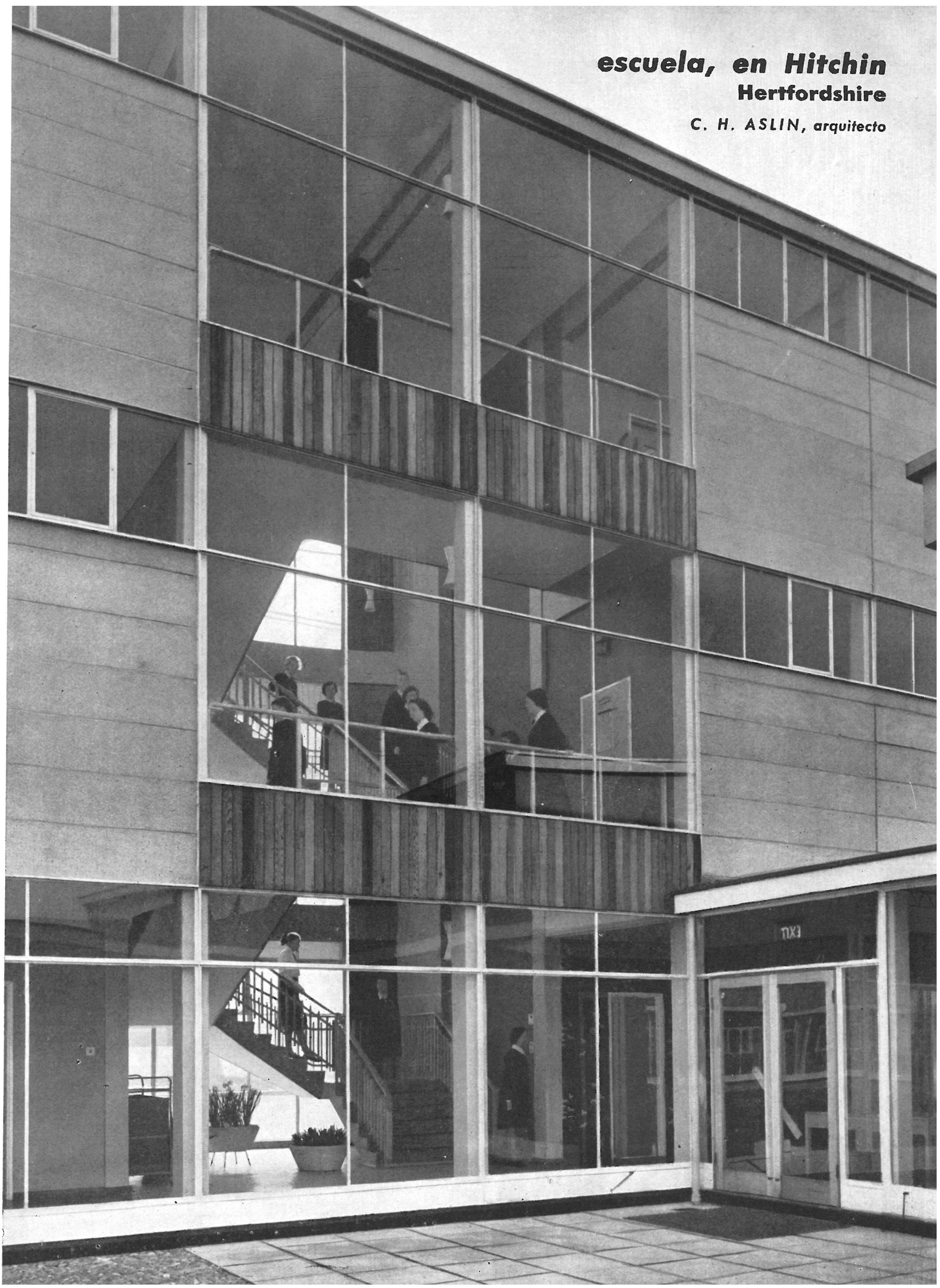




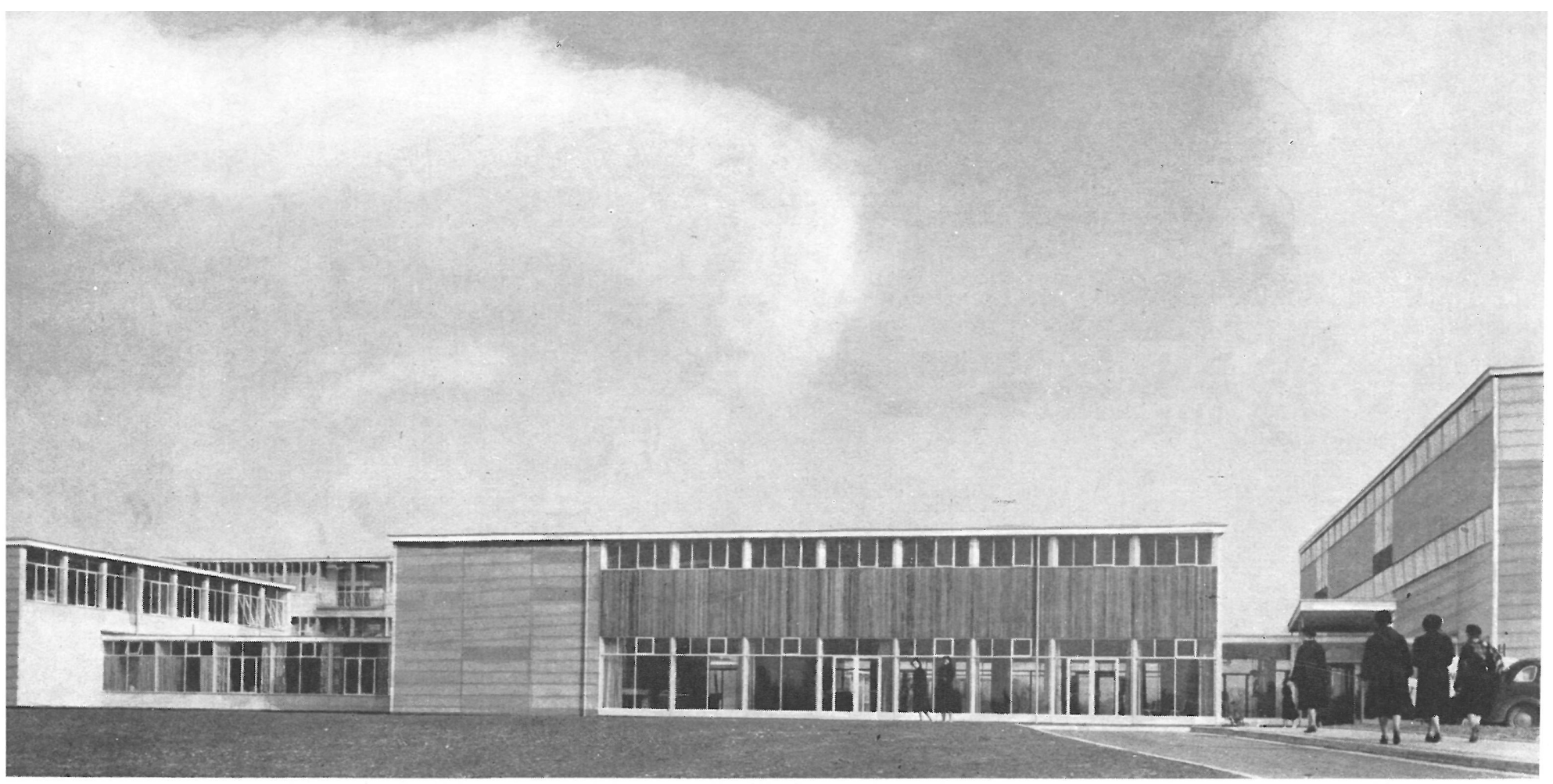

$141 \cdot 50$

En las afueras de Hitchin, junto a la carretera de Bedford y en la cima de una colina, se eleva la escuela femenina de enseñanza media con capacidad para seiscientas chicas. Su posición elevada ha permitido cuidar sus cuatro fachadas, disfrutándose de buenas vistas sobre los alrededores.

El centro principal de la escuela, es decir, la sala de reunión, comedores, hall de entrada y gimnasio, forman un edificio de una sola planta, que sirve de enlace de los dos bloques de tres plantas en los que se distribuyen las clases.

El ala de clases prácticas contiene las aulas de artes y talleres, laboratorios y sala de música.

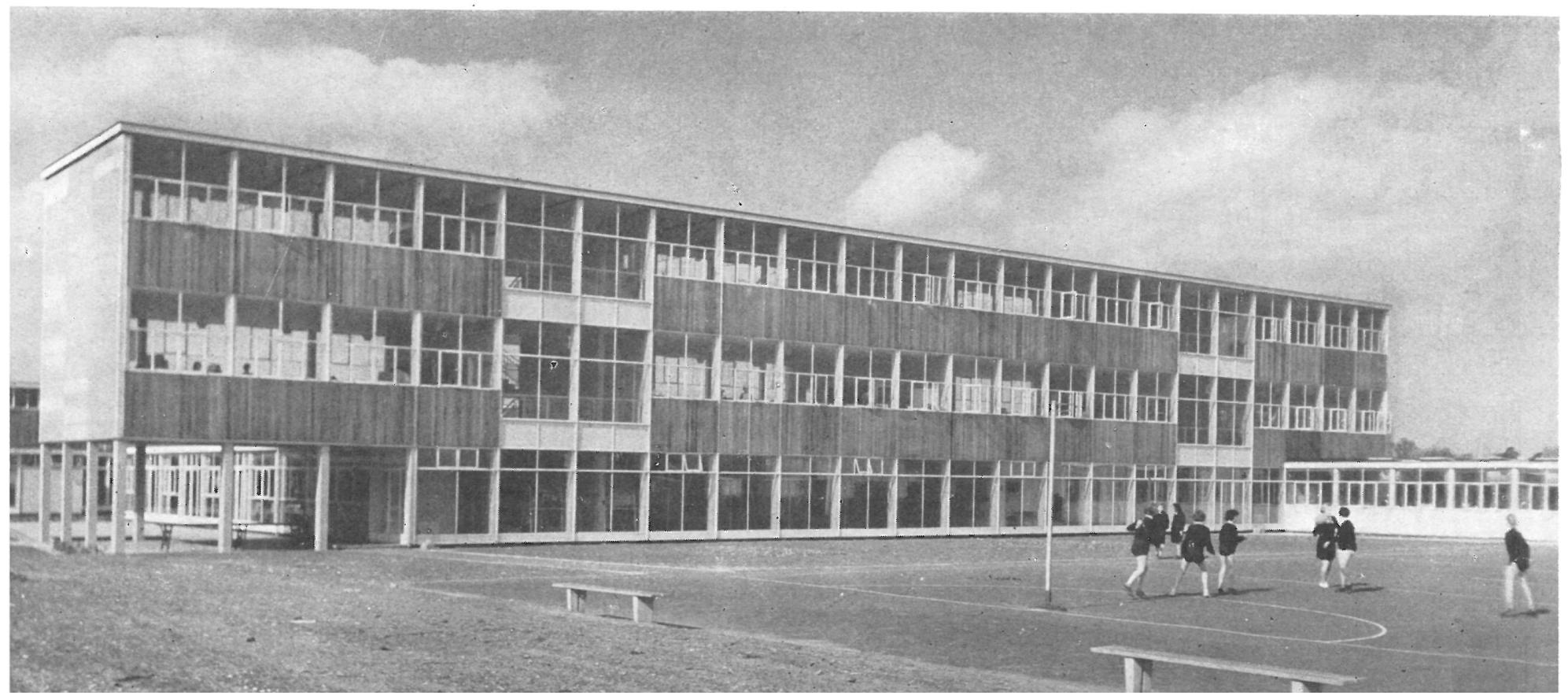



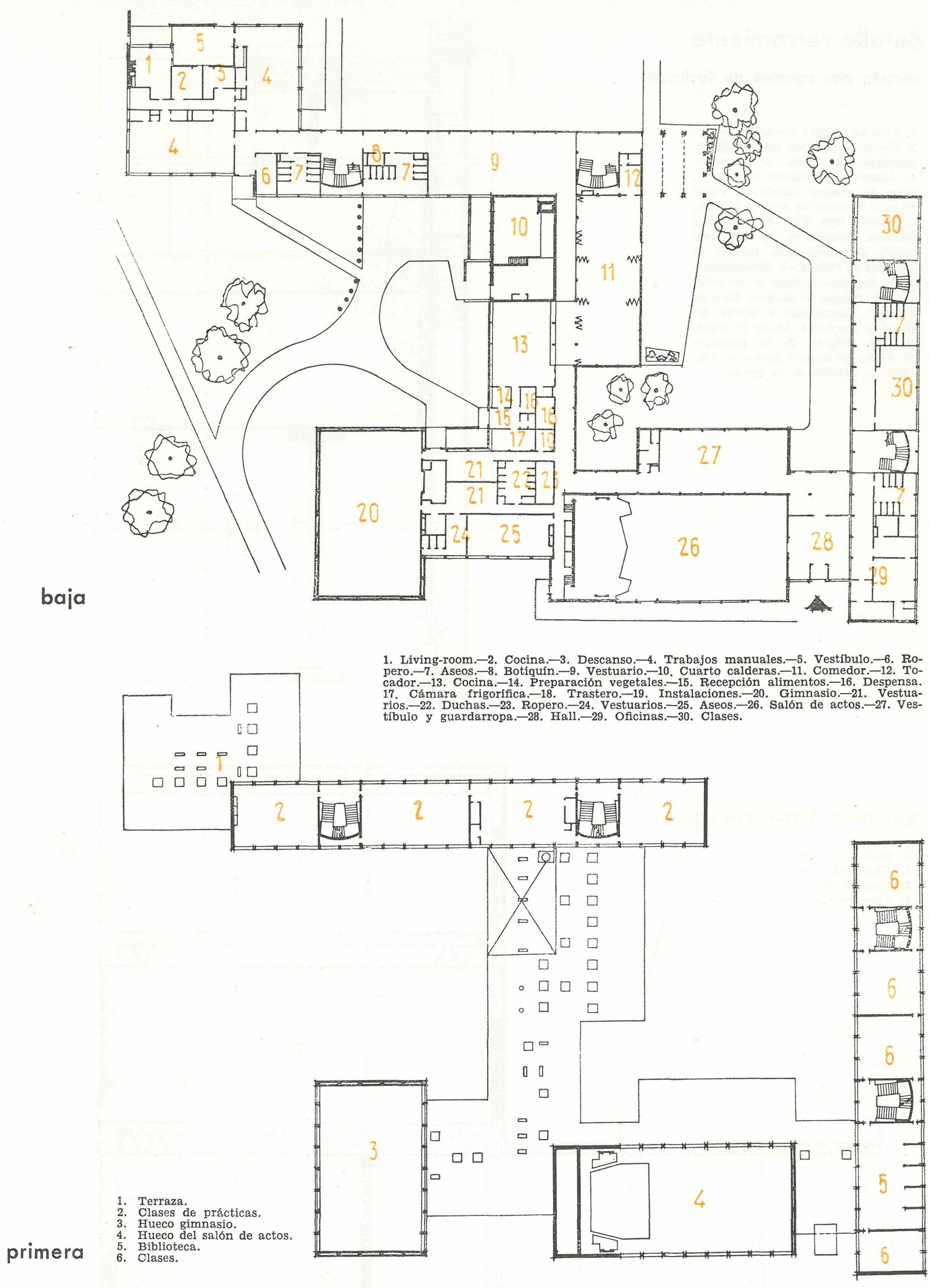


\section{detalle cerramiento}

sección por paneles de fachada

1. Taco de madera clavado al cerco. 2. Fieltro bituminoso con arcilla refractaria. - 3. Fibra de vidrio. 4. Aislante de asbesto clavado al clavado al cerco de madera blanda. 6. Bloque tipo FW.-7. Taco con creosota, clavados en las caras verticales del cerco para retener el material de relleno.-8. Revestimiento del forjado.-9. Material de relleno.-10. Bloque de madera dura de 3 " $\times 1 \frac{1}{2}$ ", atornillado a través del panel al cerco.-11. Línea de soporte. -12 . Angulo de la peana. 13. Peana de madera dura.-14. Tornillo de fijación de la peana. cerco de madera blanda.-5. Papel

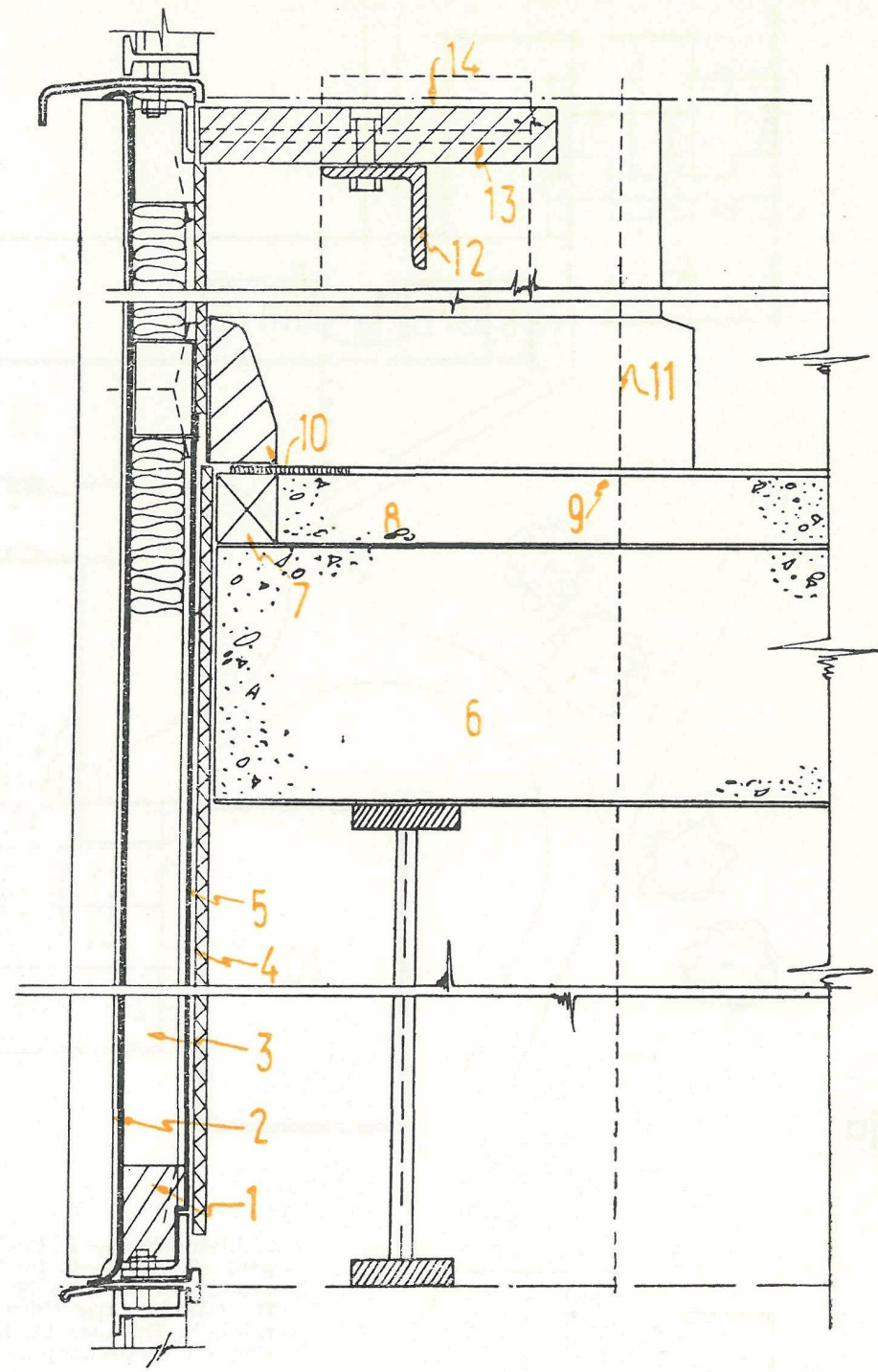

\section{sección transversal}

1. Hall de entrada.

2. Clase reducida.

3. Clase normal.

4. Clase práctica.

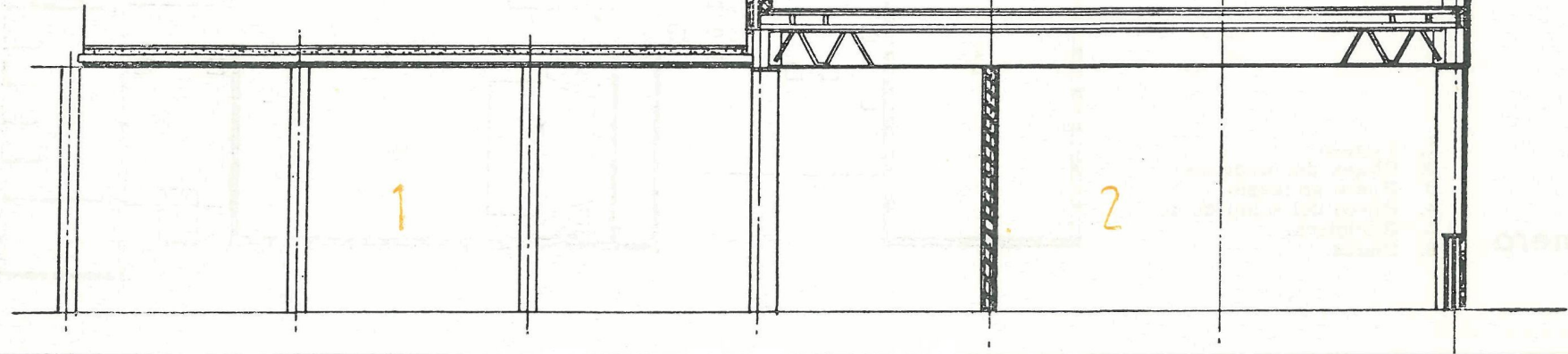


Por ser la escuela un liceo femenino no hacian falta talleres con equipos pesados

$\mathrm{y}$, por tanto,

su distribución en plantas superiores no ofreció ninguna dificultad.

Las aulas de artes del hogar (cocina, costura...), dedicadas a las alumnas mayores, tienen una gran importancia.

Como los bloques altos están orientados de norte a sur, sus fachadas a este y oeste permiten la iluminación de las clases por ambos lados.

En el bloque general se encuentran las clases tranquilas,

la biblioteca

y las clases individuales utilizadas por alumnas mayores como estudio.

La circulación en el centro de la escuela se resuelve alrededor del patio, que, integrado con el cuerpo bajo, contribuye a dar la impresión de gran amplitud espacial en el centro de la escuela, a la vez que sirve

de enlace entre bloques.
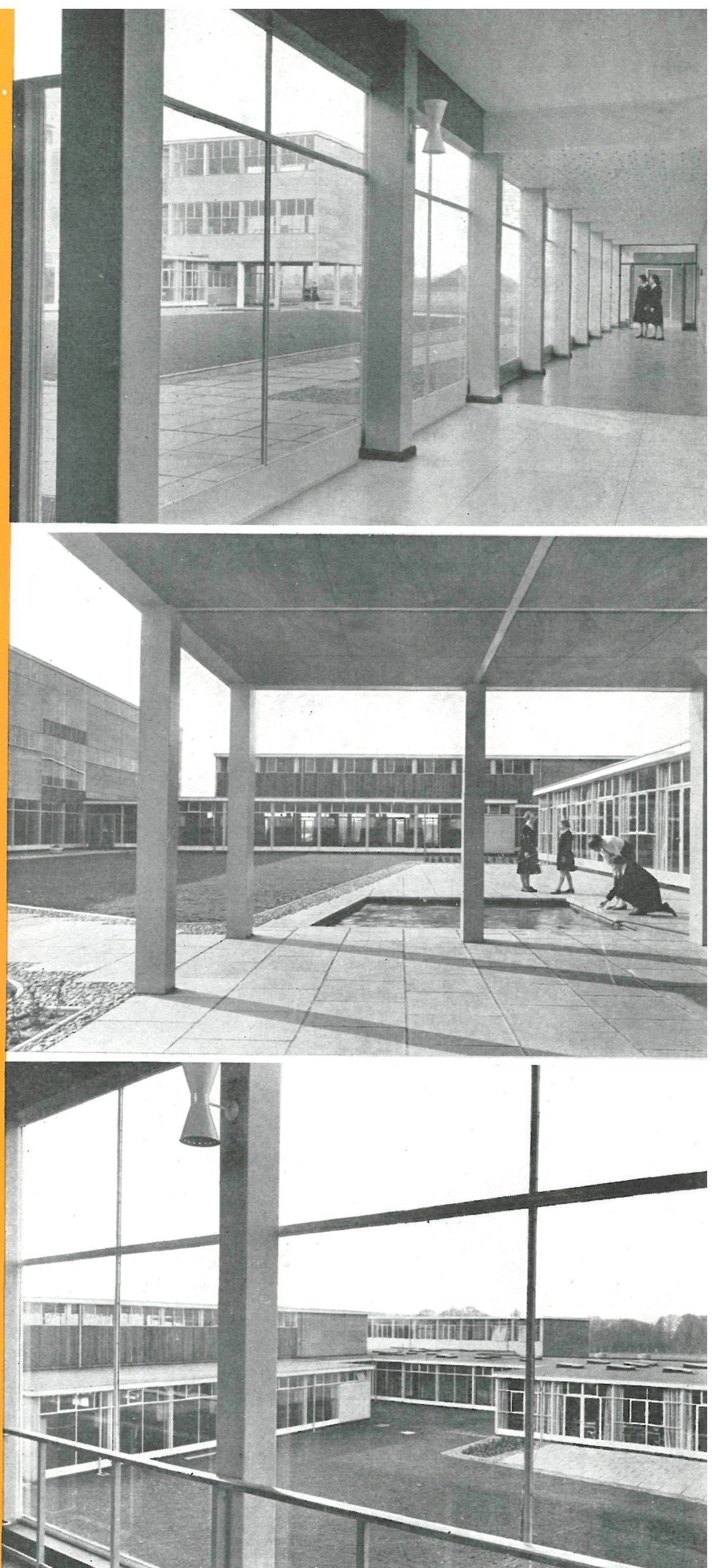


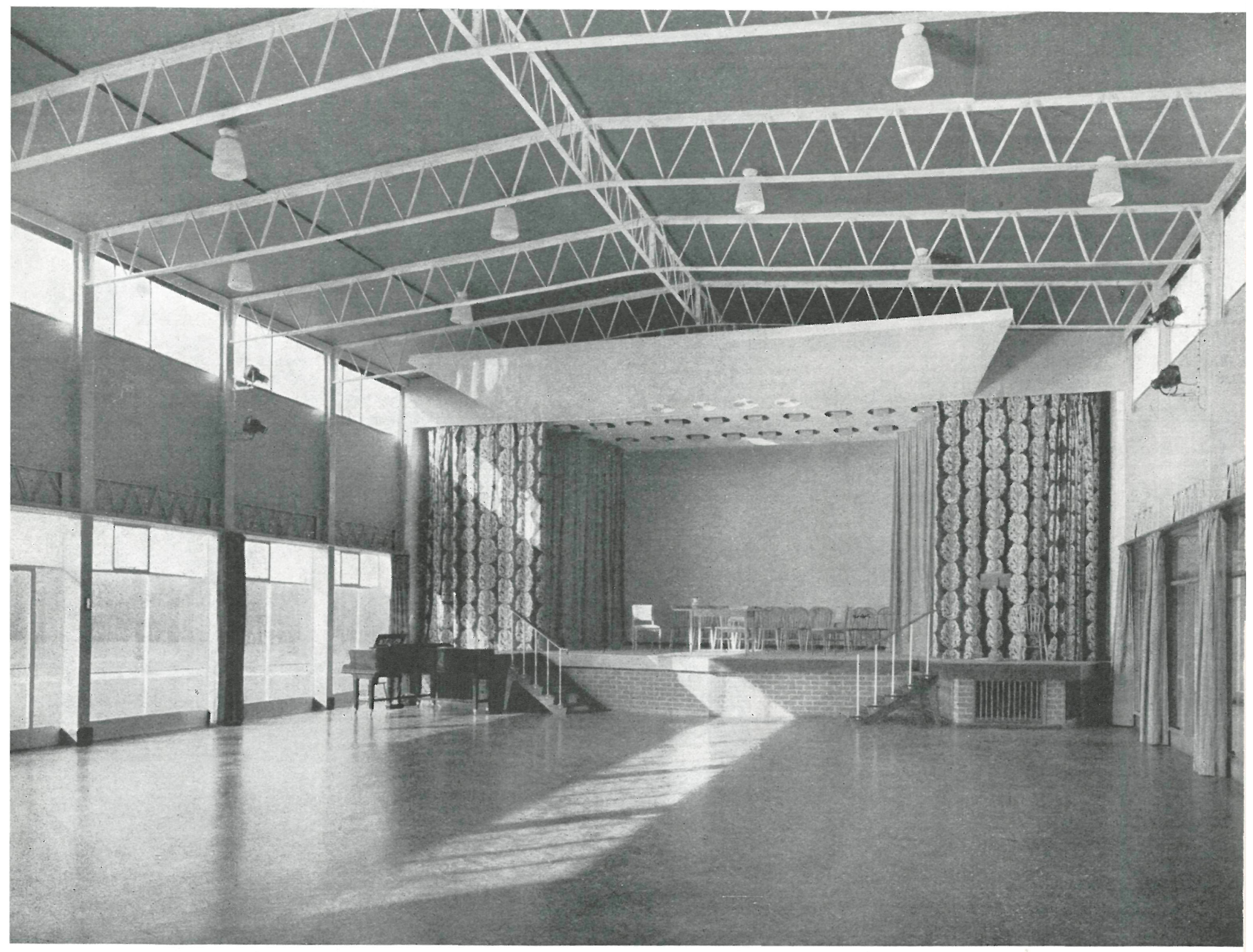

La construcción está resuelta con una estructura ligera, normalizada con un módulo de 3,20 metros, y cuyos soportes están formados por tubos metálicos de sección cuadrada, de $14 \mathrm{~cm}$ de lado, mientras que las vigas son de celosía de acero soldado.

El cerramiento exterior está constituído por cristal y paños ciegos de piezas premoldeadas de hormigón.

En la cubierta se han empleado bloques huecos de hormigón premoldeado con capa aislante. revestidos con dos capas de fieltro bituminoso. 